\title{
LITERATURA, LOUCURA E AUTORIA FEMININA: MAURA LOPES CANÇADO EM SUA AUTORREPRESENTAÇÃO DA ESCRITORA LOUCA
}

\author{
Gislene Maria Barral Lima Felipe da Silva
}

\begin{abstract}
RESUMO: Este artigo analisa a obra Hospício é Deus (1965), de Maura Lopes Cançado, na qual se apresenta uma perspectiva feminina sobre a insanidade a partir da autorrepresentação de uma escritora louca. Além de peça de inegável qualidade estética, a obra em estudo carrega em si uma elevada carga de subversão porque lida com a desestruturação da estabilidade do universo patriarcal e põe em questão não apenas os pressupostos da lógica racional, mas sobretudo os valores literários canonizados, ao acolher e legitimar a voz de uma minoria durante muito tempo silenciada. Ao extrapolar o espaço da interioridade e atingir o campo da cultura, a obra se reveste de valor literário e político.
\end{abstract}

PALAVRAS-CHAVE: autorrepresentação literária, literatura brasileira, criação literária, loucura e literatura.

ABSTRACT: This article analyzes the work Hospício é Deus (1965), by Maura Lopes Cançado, in which it is presented a feminine perspective about the insanity from the selfrepresentation of a mad writer. Beyond the undeniable aesthetic quality, the work is extremely subversive because it deals with the destructuration of the patriarchal universe stability and puts in question the presupposing values of the rational logic, and the canonic literary values, when receiving and legitimizing the voice of a minority silenced during so much time. Thereby, when the work surpasses the space of the interiority and reaches the field of the culture, it acquires a politician and literary value.

KEYWORDS: literary self-representation, Brazilian literature, literary creation, madness and literature.

Muitas escritoras brasileiras contemporâneas, como Lya Luft, Lygia Fagundes Telles e Clarice Lispector, entre outras, criam em suas obras várias personagens que mergulham na experiência trágica da loucura como resposta a um conflito familiar, social ou existencial. Se nelas a loucura é representada a partir de um olhar que a vê do exterior, ou seja, é uma interpretação da condição de louca no universo representado na obra, em Hospício é Deus (1965), de Maura Lopes Cançado, pode-se ler uma versão da loucura por dentro. Produzida por uma mulher rotulada socialmente como louca, a obra, que se encontra à margem do padrão literário oficial, apresenta uma perspectiva feminina sobre a insanidade.

Hospício é Deus é escrito em forma de diário, cobrindo o período de 25 de outubro de 1959 a 7 de março de 1960. A narradora-personagem projeta-se no texto 
como uma mulher adulta, exercendo a profissão de jornalista, com textos publicados no periódico carioca Jornal do Brasil, e com o propósito de tornar-se escritora, especialmente de contos. Natural da cidade de São Gonçalo de Abaeté, no estado de Minas Gerais, casou-se aos 15 anos, teve um filho, criado pela avó, e um ano depois seu casamento estava desfeito. Encontra-se na condição de interna no hospital psiquiátrico Gustavo Riedel, situado no bairro do Engenho de Dentro, no Rio de Janeiro. Até o momento da narração, é a terceira vez que se interna nesse tipo de instituição, autorizada por seu médico após insistente pedido dela. Internada a primeira vez aos 18 anos em um confortável sanatório particular, durante uma crise de depressão, também a seu pedido e com conivência do médico, a narradora parece em curso com o que o antropólogo social Erving Goffman identifica como "carreira moral"1 de um doente mental.

Em todos os dados objetivos, coincide a trajetória da narradora-personagem com a da autora da obra (MENDES, 2008, p. 4). Daí a impressão de que o diário possui um caráter autobiográfico, e isso não contraria a afirmação de que o eu do discurso constitui uma representação ou ficcionalização do eu da escritora, isto é, a autora cria a personagem Maura Lopes Cançado ${ }^{1}$, enredando o leitor na sua teia de palavras, imagens, decepções, medos, desespero: "Estou brincando há muito tempo de inventar, e sou a mais bela invenção que conheço. Antes me parecia haver um depois. Agora não me parece haver além de agora. Há muito tempo o tempo parou. - Onde? Sou o marco do esquecimento" $\left(H D^{1}, 210\right)$.

Como num prólogo, as páginas iniciais do diário apresentam um mergulho no passado da personagem, realçando fatos de sua infância e seus sentimentos em relação a eles. No relato de sua formação pessoal, atribui à remota infância - de onde recompõe sua formação psicológica - a gênese de sua loucura. A imaginação exacerbada, a insegurança e o medo constante da morte, do escuro, das chuvas e das pessoas ocupam papel central em sua formação psíquica, que remonta às concepções morais íntimas em choque com dificuldades e obstáculos que enfrenta a fim de chegar à maturidade. A sexualidade reprimida e o temor religioso levam-na a um profundo complexo de culpa que lhe provoca atitudes extremas, como a de deitar-se no chão e gritar desesperadamente, como se a expulsar de si "algo escuro, indefinível, insuportável" $(H D$, p. 25$)$. Essa extrema sensibilidade com a qual ela não sabia lidar já seriam indícios 
de sua personalidade exigente e levam-na a perceber-se uma menina "excepcional, monstruosamente inteligente e sensível, perplexa e sozinha", "uma candidata aos hospícios onde vim parar" (HD, p. 20).

$\mathrm{Na}$ autoanálise que faz por meio da escrita, a narradora enraíza sua personalidade egocêntrica na superproteção da família e, com isso, na incapacidade de lidar com sentimentos adversos e frustrações, aliadas a uma excessiva importância dada a tudo que adviesse de sua pessoa. Construiu de si uma autoimagem extremamente positiva, alguém que, na infância, tornou-se "objeto de atenção de toda família, (...) orgulho de [seu] pai" e alvo da admiração de todas "as pessoas, mesmo as desconhecidas, [que] jamais deixavam de [lhe] prestar atenção" (HD, p. 13). Por outro lado, se sua trajetória inicia-se plena de afeto, atenção e cuidados, logo se esboroa com a entrada na adolescência e um casamento precoce, precipitado e efêmero, que lhe desqualifica com a condição inaceitável e desprezível, para o contexto social repressor dos anos 1950 e 1960, de mulher divorciada ${ }^{1}$. Então sua situação cômoda e privilegiada na vida familiar se inverte: projetando-se no espaço social, é julgada, desprestigiada e desqualificada, havendo mesmo o relato da sensação de ter sido, de algum modo, traída ou abandonada por aqueles que, na infância, sustentaram e deram curso à construção de sua personalidade extravagante, exigente. Mais que sua nova e inconveniente condição proporcionada pela separação conjugal, o preconceito e os valores morais entendidos por ela desde então como absurdos e insensatos, incompreensíveis e revoltantes, destroem-na socialmente.

À frente do tempo histórico do espaço provinciano onde vivia, de pensamento independente, já leitora de filósofos como Nietzsche e informada sobre os acontecimentos mundiais, a narradora julga-se, após desfeito o casamento, na condição de pessoa livre e emancipada. Por isso, recebe atordoada e insegura o desrespeito e o desprezo como punição por infringir as normas de conduta moral feminina. A imaturidade e o desejo de autopreservação impedem-na de romper com a necessidade imperiosa de atenção e a submissão aos julgamentos sociais; daí a frustração, o sentimento de insuficiência e a inadaptação ao mundo.

$\mathrm{Na}$ infância e adolescência, o desmedido e constante desejo por tudo que não possuísse e a imediata insatisfação e desprezo com o obtido, e com tudo mais ao seu redor, amenizam-se com o refúgio nos devaneios de uma imaginação exacerbada: 
"Ainda o que me davam parecia pouco. Formou-se no meu ser séria resistência às pessoas e coisas conhecidas. Então inventei o brinquedo sério do FAZ DE CONTA. E me elegi rainha..." (HD, p. 19). Na vida adulta, porém, os sonhos são substituídos pelo mergulho em um estado de total descompromisso e irresponsabilidade, representado como loucura. Logo, o enlouquecimento significa um modo de estar sozinha e livre de qualquer compromisso com a lógica masculino-repressiva dominante, escapando-se ao dever de desempenhar o papel da mulher, tal como ele se desenhava então.

Se o descontrole emocional, as reações impulsivas, as agressões gratuitas às pessoas, os acessos de raiva e a mudança de humor, passando de um extremo a outro, são suficientes para denunciar a perda de sua capacidade de discernimento, sua escrita excessivamente lúcida, crítica, bem articulada, com um vocabulário apurado e preciso é capaz de camuflar sua "patologia psíquica". Seu absoluto domínio sobre sua ficção só concorreria para a confirmação de uma loucura patológica caso esta pudesse se justificar como "um mal nobre sem o qual a criação não seria genial” (BERRY, 1991, p. 130). Mas, de fato, também há a loucura "que torna o homem ainda mais solitário e diferente dos seres comuns" (id., ibid.), que se instaura como uma modalidade de purificação, de grandeza com que a narradora procura dominar sua tendência autodestrutiva.

Sua escrita traduz-se como uma bem sucedida experiência literária de enfrentamento da angústia e depressão, enquanto os desregramentos que comete colocam-se mais no campo de uma moral social (um desejo de "anarquizar com as convenções”, segundo seu médico, Dr. A.) do que propriamente de uma doença mental ou de uma linguagem desviante. Contudo, diante da dificuldade dos especialistas médicos em rotular o mal-estar que acomete a escritora, é também a escrita que traz à tona a palavra "esquizofrenia" - enunciada pelo escultor e amigo Amílcar de Castro para a possibilidade de um diagnóstico psiquiátrico: “- Leia, Amílcar, vê se gosta. Não ligue aos rabiscos, que são de dona Auda. Era a página do diário em que converso comigo mesma. Ele leu atentamente, - Mas isto é esquizofrenia pura. Foi dona Auda quem escreveu? - Não, eu" (HD, p. 221).

A narradora constrói de si própria uma imagem dúbia, instável, volúvel. Ao longo da narrativa, estados de espírito contraditórios se alternam e se mesclam, como confirmação de sua instabilidade emocional: ao mesmo tempo em que critica e procura desacreditar, agredir e rejeitar a moral burguesa, a sociedade em que se formou e o 
sistema psiquiátrico, ela busca desesperadamente ser aceita por esse mundo e se pune por não conseguir se adequar a seus padrões: "Considero-me uma paciente de 'elite', com direito a exigir a mesma condição do terapeuta" (HD, p. 205). Contudo, por apresentar um comportamento que não condiz com as expectativas de sua classe social, ela é rejeitada no colégio interno, nos hotéis familiares onde busca viver em Belo Horizonte e nos espaços de circulação comuns às pessoas da elite socioeconômica.

Mas a sociedade que a reprova é, em outras ocasiões, também rejeitada pela narradora, que elege para si o universo do hospício como seu espaço próprio, como a idealização de um mundo onde a loucura é a possibilidade de transcendência das limitações materiais. É ao mundo real concreto, com tantas restrições, convenções, preconceitos, que ela dirige toda sua descrença. Instaura, com isso, um movimento de transição em sua existência, rumo ao distanciamento do mundo social e ao encontro de sua interioridade, o que a lança ao desespero, sentimento esse considerado por Kierkegaard (2002, p. 25.) como intrínseco ao ser humano. Desespero que só pode ser sentido por aquele que, na busca do autoconhecimento e de sentido para sua existência, mergulha o mais fundo em si mesmo e vê que não pode se libertar do seu eu, o que a personagem capta com nitidez ao comentar: "Percebo uma barreira em minha frente que não me deixa ir além de mim mesma" (HD, p. 44). E dessa introspecção, o sujeito vem à tona pela escrita, conscientizando para si a essência de seus desejos, emoções, de sua presença e história.

Então a personagem busca o hospício como um lugar fora do mundo e a loucura como uma proteção contra esse mesmo mundo onde fracassa em todos os seus movimentos por autonomia e liberdade. O hospício é, assim, uma oportunidade de introversão e encontro consigo própria: "O que me traz para aqui? [...] Analiso cada passo meu. Sofro cada gesto. Odeio estar aqui - mas vim. [...] Meu egoísmo é tão grande que não me permite esquecer-me um pouco: sou, sou, sou. Naturalmente a dor não absorve - translúcida” ( $H D$, p. 77). Mas, paradoxalmente, esse mundo desejado, romanticamente idealizado, e transmutado no espaço físico do hospício vai ser repudiado como espaço hostil, porque lugar do convívio indesejável com pessoas aquém de seu nível social, cultural, intelectual. Outro exemplo da dubiedade de seu discurso é que, mesmo após repudiar a violência com que as internas são tratadas no manicômio, ela defende que algumas delas mereçam realmente ser castigadas, devido a 
seu comportamento irascível. Já em outras passagens, ela descreve terna e poeticamente as cenas das loucas dançando livres e alucinadas nos pátios e telhados.

Ainda que sua maior crítica seja à moral da elite burguesa mineira, da qual participa como membro e como intelectual, e inevitavelmente assume os valores, a obra ecoa a visão de mundo dessa classe. Debatendo-se entre seu mundo particular - a partir do qual extrai seus parâmetros de elocução - e a consciência das deficiências desse mundo, a visão que a narradora constrói do hospício coloca a maioria daquelas personagens em perversa situação de inferioridade: “As mulheres são geralmente burras e sou inteligente" (HD, p. 149). A discriminação continua na divisão das internas em doentes mentais e loucas e, a partir disso, da formulação de seu próprio conceito de loucura. Nessa separação, as doentes mentais encontram-se em nível abaixo das loucas, que são aquelas que ela acredita terem alcançado um estágio espiritual elevado; aquelas que, já tendo superado a esfera material do mundo, ingressaram em um estado de completa inocência, grandeza, liberdade, dignidade ( $H D$, pp. 36-7).

Minguados os recursos da herança que a mantinham em caras casas de saúde, a narradora se vê a compartilhar o mesmo espaço degradante em que são empilhadas as loucas miseráveis das classes populares. A experiência do internamento nesses locais lhe permite distanciar-se de sua identidade social e lhe dá base para comparação de sua vida atual com a anterior à entrada naquele hospício. A ideia de fracasso provém da consciência de que ela não se considera uma pessoa comum, mas alguém cuja superioridade intelectual, social e econômica seria capaz de lhe garantir um lugar privilegiado em todas as instâncias sociais, inclusive nas instituições por onde passasse. Seu passado interfere em sua representação já que é a partir da perspectiva de uma mulher pertencente à elite socioeconômica e cultural que ela se posiciona, e faz questão de marcar seu lugar de fala: "A família de papai, Lopes Cançado, tem grande prestigio financeiro, social e político em nosso Estado; é chata, conservadora, intransigente, como todas as 'boas' famílias mineiras" (HD, p. 17); "Papai: Sempre ouvi dizer que muitas de suas fazendas lhe eram desconhecidas por estarem distantes. Filho de família rica, gastou tôda sua herança quando jovem, casando-se depois com mamãe e recomeçando a vida..." (HD, p. 14); "Somos descendentes de nobres belgas, parece-me" (HD, p. 18). Entretanto, o elevado status social e financeiro não a livra de lacunas que lhe parecem 
abissais: "Minha necessidade de afirmação se dava nas vinte e quatro horas do dia" (HD, p. 28); "Sofria de carência afetiva, era desleixada e indisciplinada" (id., ibid.).

Ligada à sua classe de origem, letrada, com formação superior à média da época, confessa não saber dialogar com pessoas de nível intelectual e social inferior ao seu. Ela própria se distingue socialmente, distinção que se reflete na própria linguagem a ser utilizada com as funcionárias do hospício, supostamente inferiores: "Sou escritora, minha família é rica e importante - esta mulher não serviria para cozinheira da minha casa. Devo impor-me. Como? Em que língua falar-lhe?" (HD, p. 47). E assim ela segue julgando o mundo e as pessoas com rigor e severas exigências, quando não com desprezo e humilhação. Mas a loucura se torna traço homogeneizador dos indivíduos quando atinge um grau crônico, que a narradora julga "santificação". Por outro lado, esse estágio, que já foi tido como "degradação última e absoluta inocência" (FOUCAULT, 1993, p. 158), quando visto de fora se mostra desesperador, tanto que a narradora o compara à descrição do inferno de Dante na Divina Comédia, e, por isso, ela o teme como um ponto para o qual avança:

Até quando haverá pátios? Mulheres nuas, mulheres vestidas mulheres. Mas esta mulher, rasgada, muda, estranha, um dia teria sido beijada. [...] Não aceito nem compreendo a loucura. [...] Estou desesperada. Sempre fico assim quando vou lá. Tenho mêdo. Não freqüento o pátio, e sempre que estou aqui gozo de regalias que as outras nem ao menos conhecem. Mas até quando vai durar isto: Até quando estarei livre do pátio? (HD, p. 226).

Com o passar do tempo e a constatação de suas diferenças em relação às demais internas, ela reconhece se beneficiar de um sistema de privilégios dentro do hospício: "Minha condição no hospital é especialíssima; nenhuma doente goza das regalias que gozo" (HD, p. 256). E assim reafirma sua superioridade sobre as demais, pelos atributos que todos lhe reconheceriam: beleza, sensualidade, ousadia, inteligência, perspicácia, erudição.

A partir de sua autorrepresentação, o leitor pode visualizar a estranha figura de uma mulher louca, bela, sedutora, a tudo percebendo com profundidade e agudeza de espírito. Imagem altamente favorável, exceto pelo fato de constantemente também vislumbrá-la a agredir guardas e colegas, a se despir publicamente ou se dirigir acintosamente às diversas personagens, em um comportamento que contrasta paradoxalmente com o alto conceito que a narradora constrói de si própria. O desejo de 
total libertação, mas principalmente de atenção e compreensão, culmina com a tentativa de suicídio. Para a narradora, a morte física bem poderia solucionar definitivamente toda a angústia, já que a morte espiritual, representada pela loucura, parece tê-la tornado ainda mais lúcida, uma lucidez que chega a ultrapassar a compreensão racional:

\begin{abstract}
Avanço, cega e desnecessária - não é este o meu tempo. Fora da vida, do mundo, da existência - apesar de enclausurada. Que sou eu?? Não importa. Quem poderia julgar-me? [...] Obrigada a marchar como os outros, aparentando ser o que não sou, ou perturbo a ordem [...] passarei, sem conseguir minha identificação. E não serei jamais alguém, freqüientei um tempo errado ( $H D$, pp. 241-2).
\end{abstract}

Dessa forma, sua loucura consiste em estar no mundo e não poder absorvê-lo nem compreendê-lo. A escrita tem papel crucial nessa jornada de autoconhecimento. Ela constitui, assim como a loucura, uma tentativa de superação do vazio interior, da angústia e do desamparo. A experiência do suicídio e o desejo de autodestruição são postergados, uma vez sublimados pela transposição dessas imagens para a experiência literária. A consciência de sua loucura como material e espaço de criação leva a narradora a identificar-se com grandes artistas loucos: Van Gogh, Gauguin, Rimbaud, Dostoievski, e com filósofos como Gide e Nietzsche (HD, p. 149). Ademais, a todo momento, ela se reafirma como escritora que precisa cuidar de sua literatura e que conhece a força literária de sua escrita. Formula conceitos sobre estética, moral, ética, e registra suas reflexões acerca da criação e da crítica literária, de obras e autores consagrados. Fatos literários e artísticos da época são invocados com frequência. Figuras que sobressaem na literatura brasileira, como Assis Brasil, Ferreira Gullar, Maria Alice Barroso e outros que participam do movimento literário concretista à época tornam-se personagens de sua narrativa, registrando seu convívio intenso com o mundo literário.

Maura Lopes Cançado se narra na condição de personagem de uma experiência trágica sobre a terra: a de não pertencer a este mundo e a nenhum outro e nisso reconhece a inutilidade de uma fala contínua, esvaziada de sujeito. E se "o louco é aquele cujo discurso não pode circular como o dos outros: [uma vez que] pode ocorrer que sua palavra seja considerada nula e não seja acolhida, não tendo verdade nem importância" (FOUCAULT, 1988, pp. 10-1), também na escrita literária a narradora reafirma a consciência da ineficácia de seu discurso, a impossibilidade de, como insana, fazer com que sua palavra seja recebida e validada diante da autoridade hospitalar. Por 
isso, revela: "Mas como chegar a ele, se não me ouve, me encara como psicopata - e pronto?” (HD, p. 99). O que corresponde, simbolicamente, à consciência de que também no sistema literário sua obra não virá a ser aceita, já que socialmente ela também não se afirma como mulher, descasada, no contexto sociocultural da época.

Diante dessa resistência, a escrita é, para ela, o espaço sagrado de que precisa cuidar: "meu diário é o que há de mais importante para mim. Levanto-me da cama para escrever a qualquer hora, escrevo páginas e páginas - depois rasgo mais da metade, respeitando apenas, quase sempre, aquelas em que registro fatos ou minhas relações com pessoas" ( $H D$, p. 186). O trabalho com a palavra impõe-se como uma exigência interior, de modo que sua maior luta consiste em equilibrar esse movimento ao mesmo tempo de entrega (“Meu conto 'O Sofredor do Ver' está me custando. (...). É o conto que mais tem exigido de mim. Considero-o muito cerebral. Talvez seja minha obra prima" - $H D$, pp. 86-7) e de resistência (“Até quando seria escritora em potencial? Até quando, se não escrevo? Apenas um futuro me acenando brilhante? [...] Por que não me deixaram também escritora? Esta consciência me mata. Não quero nada, não desejo nada" - $H D$, p. 260).

Ao falar a partir de sua tumultuada experiência do internamento espontâneo em uma casa de reclusão de loucas e transformá-la em matéria literária, a autora traz a voz socialmente rejeitada e apartada da alteridade para o centro de reflexão. Ela faz questão de marcar no discurso seu lugar de fala e sua condição de interna no sistema psiquiátrico, a partir dos quais se supõe que tenha legitimidade para abordar aquela realidade: “Aqui estou de nôvo nesta 'cidade triste', é daqui que escrevo. Não sei se rasgarei estas páginas, se as darei ao médico, se as guardarei para serem lidas mais tarde. Não sei se têm algum valor. Ignoro se tenho algum valor, ainda no sofrimento" (HD, p. 43).

Também afirma seu poder de decidir o destino a dar à sua escrita e o direito a formalizar no texto seus embates mais íntimos, o que é uma estratégia discursiva que busca dar confiabilidade ao discurso da narradora. De sua loucura, contudo, fica a sugestão de uma normalidade hipertrofiada, uma extrema lucidez que the permite vislumbrar em sua escrita não apenas um espaço de interação entre interlocutores (BAKHTIN, 1997, passim), mas sobretudo a consciência do poder de dar acesso, como uma porta-voz, à experiência daqueles que passaram para uma realidade inacessível ao 
indivíduo comum: “Com o que escrevo poderia mandar aos 'que não sabem' uma mensagem do nosso mundo sombrio. Dizem que escrevo bem. Não sei. Muitas internadas escrevem. O que escrevem não chega a ninguém - parecem fazê-lo para elas mesmas" (HD, p. 43).

Embora admita sua contumácia em falar de si própria, e sua escrita se volte obsessivamente para o eu, reconhece que sua condição de escritora exige que dê conta, em um âmbito mais amplo, do sofrimento humano situado aquém dos limites dos muros do hospício. E mesmo que se afirme como egocêntrica, megalomaníaca e doente do eu, ela se trai ao verbalizar o desejo de homenagear cada interna com um conto, desde que isso pudesse melhorar um pouco a condição de cada uma, como o fez com Auda, no seu "Introdução a Alda", o qual despertou a atenção de todos para o drama da colega.

Sua consciência da condição de escritora emerge nessa autodeterminação de escrever por aqueles que não escrevem, falar pelos que não falam, enfim, tentar reconstituir um pouco daquela realidade que, pensa ela, "só o cinema será capaz de mostrar" (HD, p. 275). Ainda que, em muitos momentos, ela se movimente desconfortavelmente entre uma elite letrada - que detém o poder de fala e encarna o discurso ideológico dominante - e a classe marginalizada, acaba se reconhecendo como uma consciência que fala à margem da sociedade, e, dessa perspectiva, ela pode dar voz àqueles que, de outro modo, não teriam como se manifestar.

Mas a consciência da importância de sua voz, embora titubeante ante a incerteza de futuras repercussões de seus registros, não reduz sua escrita ao nível de um documento, que se quer colado à história cotidiana. Não obstante narre no diário, com forte carga literária, sua vivência no mundo do hospício, a personagem se consome em busca de uma maior estetização e ficcionalização de sua realidade por meio da prosa poética dos contos que escreve. Os contos que está produzindo, depois publicados na coletânea intitulada $O$ sofredor do ver, retomam cenas, fatos e experiências de seu livro de memórias e os transpõe para um novo gênero, pleno de metáforas, imagens, de conteúdo estético.

O engajamento da escritora apresenta ainda maior vigor quando ela critica os avanços de uma medicina que se preconiza como moderna, mas que, para se sustentar, precisa apoiar-se na prática da violência contra seres humanos indefesos, incapazes, inclusive respaldando-se no poder da força bruta para agir contra os mesmos: "Sempre 
aparecem homens, guardas ou doentes, seguram as doentes mais agitadas, torcem-lhe os braços para trás, dão-lhes gravatas, deixando-as roxas, sem respiração. As guardas [...] puxam-lhes os cabelos, ajudando a empurrá-la para o quarto-forte" (HD, p. 67).

À medida que a narradora vai desvelando a realidade do hospício, vem à tona a voz daquela que observa descrente o médico, que lhe aparece como o homem cientificamente fracassado, ainda que esteja buscando colocar em prática os mais recentes avanços da vanguarda médica. Ao falar de um dos médicos do hospício, a narradora registra a descrença no profissional ao definir como desrespeito o sentimento que lhe provocou a aproximação do especialista, que "entrou, [e] se pôs a ouvir interessado. Depois deu uma risada e exclamou: '- Esta é PP. Não há dúvida!'. PP quer dizer Personalidade Psicopática. Não entendi a sigla, mas senti naquêle médico, no seu ar irreverente, mesmo deboche, profunda falta de respeito à minha pessoa" $(H D$, pp. 56$7)$.

Ela não apenas compreende sua posição de marginalizada nesse contexto, mas lhe importa, sobretudo, desvelar a irracionalidade da estrutura de poder que se desdobra na realidade diária de médicos e guardas que desempenham funções complementares, na punição do louco por seu desequilíbrio psicológico, quando esse deveria ser resguardado e protegido:

Maltratavam as doentes, usavam de palavras irrepetíveis. Uma vez vi uma guarda bater numa doente catatônica. Foi no banheiro, à noite, na hora do banho. A guarda bateu ajudada por uma doente, Euza. Bateu principalmente na cabeça, dando-a de encontro à parede. Nair, Eva e eu vimos horrorizadas. A doente morreu no outro dia. Não sei se no laudo médico constou como causa a agressão. Mas ela morreu no dia seguinte à agressão. Contamos à inspetora, dona Alice Ramos Corrêa (HD, p. 276).

Nesse sentido é que Hospício é Deus, ao narrar o desconforto da personagem no mundo trágico da reclusão, discute também a literatura como espaço de viabilização das tensões psicológicas e filosóficas e de repúdio à confiança ilimitada nos recursos do sistema psiquiátrico para o tratamento da loucura.

Além da radiografia do sistema psiquiátrico que é possível se fazer a partir da visão marginalizada da narradora-hospiciada, o diário reconstitui a trajetória de uma carreira de interna psiquiátrica, registrando a dor da solidão, da culpa, da vergonha, do abandono e do medo presente na experiência solitária e singular da loucura. Num movimento emancipatório, a narradora expressa sua rejeição aos rótulos e o temor em se 
tornar número de estatísticas, colocando-se como um ser humano integral e sujeito de sua loucura: "Na minha ficha do hospital meu nome não tem valor. A ficha tem a finalidade de acrescentar mais uma psicopata para a estatística [...] Sou apenas um número a mais na estatística" ( $H D$, pp. 57-8). Esse gesto integra a loucura às experiências humanas como um estado que pode afetar a cada pessoa em qualquer situação da vida e ao qual ninguém está imune. E, ainda que a loucura permaneça como motivo de temor e ansiedade e como um fenômeno resistente à compreensão e explicação, ela não pode ser uma perturbação afastada do convívio humano.

Mesmo vivendo suas últimas e mais longas internações em hospitais públicos, e justamente por ter conhecido e vivido também em sanatórios particulares ("freqüentada por pessoas agradáveis, a Casa de Saúde era belíssima, elegante. No grande 'hall', jogávamos sinuca, bilhar, ping-pong e cartas. Eu me vestia com muita elegância" - $H D$, p. 151), sua condição privilegiada faz com que experiencie a alteridade da louca manicomizada de modo diverso da maioria dos loucos das camadas populares: "Agora, compreendo que o dinheiro suaviza tudo: até a loucura" (HD, p. 154). E ainda que a loucura seja um traço comum às personagens do hospício, as diferenças intelectuais, sociais e econômicas distanciam aqueles seres pretensamente iguais, o que faz com que a obra acabe por possibilitar discutir acerca da legitimidade da voz que fala para representar o sofrimento de uma multidão de indivíduos empilhados nos pátios de hospícios, cuja afinidade é, na maioria das vezes, a mesma origem social.

Contudo, além dessa origem, também os valores de classe, etnia, raça e gênero impregnados nos discursos que configuram a alteridade do indivíduo louco dão a ver a complexidade existente na construção das identidades. Em que pesem essas múltiplas posições identitárias, a realidade do internamento acaba por igualar indivíduos que passam a ter como denominador comum e preponderante a visão pelo mesmo como o outro da razão, aquele a quem o estigma faz com que deixe de ser considerada uma "criatura comum e total, reduzindo-o a uma pessoa estragada e diminuída" (GOFFMAN, 1988, p. 12).

E a narrativa se finda com as páginas do diário sendo amassadas pelas colegas invejosas. A destruição iminente do diário sugere que a dicção da narradora é recusada naquele ambiente já que ela não é capaz de representar com propriedade e legitimidade as suas companheiras, julgando-se "muito mais do que tudo que [a] cerca", "deveras 
mais do que tudo que [lhe] foi dado conhecer - e desprezar" (HD, p. 241). Uma estratégia narrativa que metaforiza a impossibilidade mesma da narradora em falar, ao menos na linguagem centrada, racional, lógica em que o faz, por suas iguais de infortúnio. Sorte melhor que a do diário também não cabe à própria narradora que encerra sua narrativa já fora do hospital, abandonada pelo médico a quem se afeiçoara, sem ter para aonde ir e sem saber o que sobrevirá a ela...

Se, conforme Foucault, a loucura significou, para muitos artistas, o apagamento total do pensamento e discurso (1993, pp. 505-30), para a autora-narradora, o drama psíquico emerge como possibilidade de sua atualização na criação artística. Com essa solução para a autorrepresentação da experiência e da realidade do indivíduo louco, a obra revela um espírito de denúncia e um caráter emancipatório. Produzindo em um universo dramático, a narradora encaminha seus profundos embates com o mundo e com sua subjetividade numa perspectiva diferente de tantas outras, conservadoras, perceptíveis na instituição e na sociedade que emergem do diário. Sua postura em relação à condição de louca denuncia tantas formas de marginalização criadas dentro do próprio hospício, e acaba por propor uma reflexão sobre valores e crenças excludentes e estigmatizantes em relação ao indivíduo louco. Esse texto, mergulhado no internamento e na exclusão, propicia o conhecimento mais direto e próximo da realidade do louco, enquanto a aproximação com o eu da escrita promove um contato com sua subjetividade, descortinando o véu da loucura e deixando a claro a humanidade do louco.

Além de peça de inegável qualidade estética, a obra em estudo carrega em si uma elevada carga de subversão porque lida com a desestruturação da estabilidade do universo patriarcal e põe em questão não apenas os pressupostos da lógica racional, mas sobretudo os valores literários canonizados, porquanto a escrita de uma minoria durante muito tempo silenciada traz em si, virtualmente, uma transgressão. E, atualizada na linguagem artística, a expressão do louco reveste-se de um valor político, pois extrapola o espaço da interioridade e atinge o campo da cultura (FRAYZE-PEREIRA, 1985, p. 101). 


\section{REFERÊNCIAS}

BAKHTIN, Mikhail. Estética da criação verbal. Trad. de Maria Ermantina Galvão G. Pereira. 2. ed. São Paulo: Martins Fontes, 1997.

BERRY, Nicole. O sentimento de identidade. São Paulo: Escuta, 1992.

CANÇADO, Maura Lopes. Hospício é Deus. Rio de Janeiro: José Álvaro Editor, 1965. Sofredor do ver. Rio de Janeiro: José Álvaro Editor, 1968.

FOUCAULT, Michel. História da loucura na Idade Clássica. Trad. de José Teixeira Coelho Netto. 3. ed. São Paulo: Perspectiva, 1993.

. A ordem do discurso. Trad. de Laura Fraga de Almeida Sampaio. 5. ed. São Paulo: Loyola, 1999.

FRAYZE-PEREIRA, João Augusto. O que é loucura. São Paulo: Brasiliense, 1985.

GOFFMAN, Erving. Manicômios, prisões e conventos. 3. ed. São Paulo: Perspectiva, 1990.

Estigma: notas sobre a manipulação da identidade deteriorada. Trad. de Márcia Bandeira de Mello Leite Nunes. 4. ed. Rio de Janeiro: LTC, 1988.

KIERKEGAARD, Sören. O desespero humano. São Paulo: Martin Claret, 2002.

MENDES, Karla Renata. "A literatura intimista e a denúncia em Maura Lopes Cançado". Disponível em: <http://www.unicentro.br/pet/publicacoes.html>. Acesso em: 10 ago. 2010.

TELLES, Norma. "Cidade triste". Fazendo Gênero 8: Corpo, violência e poder. Florianópolis, 25-28 de agosto de 2008. Disponível em: <http://www.fazendogenero8.ufsc.br/sts/ST14/Norma_Telles_14.pdf>. Acesso em: 12 ago. 2010.

RECEBIDO EM: 04 de maio de 2011

APROVADO EM: 15 de junho de 2011 